Meta

Journal des traducteurs

Translators' Journal

\title{
Análisis textual y jurídico comparado para la traducción: el caso de las capitulaciones matrimoniales alemanas y españolas
}

\section{Iris Holl et Pilar Elena}

Volume 60, numéro 3, décembre 2015

URI : https://id.erudit.org/iderudit/1036140ar

DOI : https://doi.org/10.7202/1036140ar

Aller au sommaire du numéro

\section{Éditeur(s)}

Les Presses de l’Université de Montréal

\section{ISSN}

0026-0452 (imprimé)

1492-1421 (numérique)

Découvrir la revue

Citer cet article

Holl, I. \& Elena, P. (2015). Análisis textual y jurídico comparado para la traducción: el caso de las capitulaciones matrimoniales alemanas y españolas. Meta, 60(3), 494-517. https://doi.org/10.7202/1036140ar
Résumé de l'article

La comparaison interlinguistique et interculturelle de types de textes juridiques met en évidence les traits distinctifs des systèmes juridiques dont ils font partie, tout en révélant les différentes conventions textuelles qui caractérisent les langues juridiques nationales. Par conséquent, l'analyse comparative peut entraîner des résultats intéressants pour la traduction de textes juridiques impliquant deux systèmes juridiques différents et deux cultures linguistiques différentes. Cet article a pour but de prouver cette hypothèse en comparant des contrats de mariage allemands et espagnols. La méthodologie proposée se fonde sur l'étude comparative juridique et textuelle. 


\title{
Análisis textual y jurídico comparado para la traducción: el caso de las capitulaciones matrimoniales alemanas y españolas
}

\author{
IRIS HOLL \\ Universidad de Salamanca, Salamanca, España \\ irisaholl@usal.es \\ PILAR ELENA \\ Universidad de Salamanca, Salamanca, España \\ pel@usal.es
}

\begin{abstract}
RESUMÉ
La comparaison interlinguistique et interculturelle de types de textes juridiques met en évidence les traits distinctifs des systèmes juridiques dont ils font partie, tout en révélant les différentes conventions textuelles qui caractérisent les langues juridiques nationales. Par conséquent, l'analyse comparative peut entrainer des résultats intéressants pour la traduction de textes juridiques impliquant deux systèmes juridiques différents et deux cultures linguistiques différentes. Cet article a pour but de prouver cette hypothèse en comparant des contrats de mariage allemands et espagnols. La méthodologie proposée se fonde sur l'étude comparative juridique et textuelle.
\end{abstract}

\begin{abstract}
Interlingual and intercultural comparison of legal text types offers evidence of distinctive features of the legal systems in which the texts are based, as well as revealing different textual conventions that characterize national legal languages. Therefore, comparative analysis can yield interesting results for translation of legal texts which involves two different legal systems and two different linguistic cultures. The aim of this paper is to prove this hypothesis by comparing German and Spanish nuptial agreements using a comparative legal and text analytical methodology.
\end{abstract}

\section{MOTS-CLÉS/KEYWORDS}

traduction juridique, linguistique textuelle comparative, traduction de textes spécialisés, contrat de mariage, droit

legal translation, comparative text linguistics, translation of specialised texts, nuptial agreement, law

\section{Introducción}

La traducción jurídica constituye un campo de amplio espectro: la existencia de marcos jurídicos diferentes (derecho ${ }^{1}$ internacional, derecho supranacional, diferentes derechos nacionales) y la posibilidad de interactuación entre ellos lleva a situaciones traslativas diversas, cada una con sus propias condiciones y exigencias.

Cabe distinguir dos escenarios de traducción jurídica principales. En primer lugar, aquel en el que la traducción se realiza entre varias lenguas, si bien dentro de un mismo ordenamiento jurídico; es decir, donde solo cambia el idioma, pero no el sistema de referencia (traducción jurídica interlingüística e intrasistémica) ${ }^{2}$. En 
segundo lugar, aquel escenario en el que la traducción no se realiza solo entre varias lenguas, sino entre varios sistemas jurídicos (traducción interlingüística e intersistémica).

El presente estudio pretende ser una aportación al segundo escenario, a la traducción jurídica intersistémica e interlingüística. En este contexto, uno de los mayores retos para el traductor lo constituye, sin duda, la falta de un sistema de referencia común. Como es sabido, cada ordenamiento jurídico, ya sea nacional, internacional o supranacional, crea su propio mundo conceptual con sus mecanismos de funcionamiento particulares (es decir, unas leyes propias, una organización de la administración de justicia y de las profesiones jurídicas determinada y unas figuras e instituciones jurídicas particulares), y los elementos que conforman ese mundo sólo cobran pleno sentido dentro de él. Así lo expresa, por ejemplo, Šarčević (1997: 230): «Each legal system has its own language and its own system of reference».

Los distintos lenguajes jurídicos, a su vez, son un reflejo de estos sistemas conceptuales diferentes y están indisolublemente vinculados a ellos, lo que ha llevado a numerosos autores a afirmar que la terminología jurídica es systemgebunden (De Groot 1991: 282; Weisflog 1996: 47) o culture-bound (Weston 1991: 11; Harvey 2000: 357). Es decir, los términos jurídicos se consideran términos culturalmente marcados. Cuando a la hora de traducir se enfrentan dos sistemas jurídicos dispares (por ejemplo, dos ordenamientos nacionales diferentes o un ordenamiento nacional y el derecho comunitario), un reto importante para el traductor reside en las incongruencias conceptuales que pueden darse. Es decir, una figura jurídica concreta puede existir en un sistema, pero en el otro, no, o puede existir pero tener una regulación distinta ${ }^{3}$. A estas incongruencias conceptuales, que tienen su origen en los distintos sistemas jurídicos, se añade el hecho de que se suelen haber desarrollado también tradiciones textuales diferentes, es decir, las clases textuales (por algunos autores denominados géneros (véase Borja Albi 2000; 2005; Alcaraz Varó y Hughes 2002) en las que se plasman los contenidos jurídicos presentan convenciones diferentes en las distintas culturas jurídicas.

Por tanto, traducir en un escenario de traducción jurídica interlingüística e intersistémica supone una tarea exigente, que requiere, por un lado, el conocimiento contrastivo de dos ordenamientos jurídicos, y, por otro lado, el conocimiento de dos tradiciones textuales diferentes. Con referencia al primer aspecto, el traductor ha de tener un conocimiento profundo tanto del sistema jurídico en el que se enclava el texto de partida como del sistema jurídico en el que se insertará la traducción. Sólo de esta forma podrá cumplir su función de mediador entre dos culturas (jurídicas) $y$, ante el trasfondo del ordenamiento jurídico de llegada (es decir, aquel en el que se utilizará el texto traducido), hacer comprensible la realidad jurídica del texto de partida, que se presupone desconocida para el destinatario de la traducción ${ }^{4}$. En lo que se refiere al segundo aspecto, el traductor también necesita conocer las tradiciones textuales diferentes de las culturas jurídicas en cuestión, es decir, tener un conocimiento detallado de las convenciones que presenta la clase textual concreta en la cultura jurídica de origen y en la de llegada ${ }^{5}$, ya que, como ha sido puesto de manifiesto por varios autores (Alcaráz Varó y Hughes 2002; Borja Albi 2000; Elena 2004), ese saber es clave para una correcta comprensión textual.

A continuación, planteamos un ejemplo concreto: la traducción de un documento de capitulaciones matrimoniales al alemán o de un Ehevertrag al español. Se 
trata de un encargo que, debido a la creciente internacionalización de las relaciones personales, no es infrecuente. Se suele producir cuando existen matrimonios mixtos entre españoles y alemanes y uno de los cónyuges tiene que acreditar en el país del otro el régimen económico al que está sujeto el matrimonio (por ejemplo, en casos de herencia o de divorcio).

El estudio se lleva a cabo aplicando el método combinado de documentación comparada sobre el tema y la estructura textual de los documentos en alemán y español (Elena 2010; Holl 2011a) y abarca dos campos diferentes pero complementarios:

- la documentación específica temática comparada sobre las capitulaciones matrimoniales en alemán y en español;

- la documentación sobre la estructura de esta subclase de textos en alemán y en español.

Para la documentación jurídica-temática se han utilizado manuales de derecho (véase anexo). La documentación textual se basa en muestras textuales auténticas que nos han sido proporcionadas por particulares y profesionales del derecho (un corpus de 10 capitulaciones matrimoniales y 10 Eheverträge).

\section{Estudio jurídico comparado}

El estudio jurídico comparado gira en torno a dos cuestiones fundamentalmente:

- el estudio del documento capitulaciones matrimoniales y del Ehevertrag; y

- los tipos de regímenes económicos del matrimonio, ya que estos, como se verá, constituyen el contenido principal de las capitulaciones matrimoniales.

\section{1. ¿Qué son las capitulaciones matrimoniales?}

Hay que tener en cuenta que el matrimonio no solo constituye una comunidad de vida, sino también una comunidad económica. Por esta razón, es necesario establecer un conjunto de normas que determinan y delimitan los intereses económicopecuniarios que rigen en las relaciones entre los esposos y entre estos y terceros (quién responde por las deudas contraídas durante el matrimonio, a quién pertenecen los bienes, cómo se reparte el patrimonio en el caso de separación, divorcio o fallecimiento, etc.). Ese conjunto de normas que regula las relaciones económicas de los cónyuges se conoce como régimen económico matrimonial o ehelicher Güterstand. Este régimen puede ser el que establezca la ley por defecto, pero también puede regularse en un documento específico, denominado capitulaciones matrimoniales, en el caso del derecho español, y Ehevertrag, en el caso del derecho alemán.

Por tanto, a modo de un primer acercamiento, podemos definir las capitulaciones matrimoniales como un documento en el que los cónyuges estipulan el régimen económico de su matrimonio.

En el derecho español, la determinación del contenido exacto de las capitulaciones matrimoniales se basa en el artículo 1325 del Código Civil (CC), que reza:

En capitulaciones matrimoniales podrán los otorgantes estipular, modificar o sustituir el régimen económico de su matrimonio o cualesquiera otras disposiciones por razón del mismo. ${ }^{6}$ 
De acuerdo con esta norma, el objeto de las capitulaciones matrimoniales radica en instrumentar las estipulaciones conyugales referentes al régimen económico del matrimonio, pero, de forma complementaria, puede referirse también a «cualesquiera otras disposiciones por razón del matrimonio».

A partir de ahí, la doctrina jurídica suele distinguir entre un contenido típico o fundamental y un contenido atípico o no necesario de las capitulaciones matrimoniales (Femenía López 2011: 124). El contenido típico viene conformado por todas aquellas estipulaciones relativas al establecimiento, la modificación o sustitución del régimen económico matrimonial. En este sentido, los cónyuges o futuros cónyuges pueden estipular que su vida económica se rija por cualquiera de los regímenes económicos previstos en el CC (como veremos, régimen de gananciales, separación de bienes, participación en las ganancias). También, en virtud del principio de autonomía de la voluntad, pueden introducir variaciones en los regímenes citados (Cárcaba Fernández 1992: 29).

En lo que se refiere al contenido atípico, este viene fundamentado en el último inciso del artículo $1325 \mathrm{CC}$, que permite el pacto de cualesquiera otras disposiciones por razón del matrimonio. Como contenido atípico, pueden formar parte de las capitulaciones matrimoniales (Femenía López 2011: 125):

- las atribuciones no modificativas del régimen económico matrimonial, en particular, las donaciones por razón del matrimonio ya sea entre los futuros cónyuges o por parte de terceros a favor de los contrayentes;

- los negocios relativos a la sucesión de los cónyuges (ejemplo: los arts. 827 y 828 CC prevén la posibilidad de que en capitulaciones matrimoniales se pueda realizar la promesa de mejorar o no a alguno de los descendientes);

- los negocios de derecho de familia no patrimoniales (reconocimiento de un hijo extramatrimonial, pactos sobre la situación de los hijos en caso de separación de hecho);

- la constitución de determinados derechos reales como el usufructo a favor del cónyuge no titular de la vivienda habitual del matrimonio;

- en general, los actos y negocios que pueden y deben constar en escritura pública.

En cuanto al contenido de las capitulaciones matrimoniales alemanas, el punto de partida es el parágrafo 1408 del Bürgerliches Gesetzbuch (BGB), que establece lo siguiente:

(1) Die Ehegatten können ihre güterrechtlichen Verhältnisse durch Vertrag (Ehevertrag) regeln, insbesondere auch nach der Eingehung der Ehe den Güterstand aufheben oder ändern.

(2) Schließen die Ehegatten in einem Ehevertrag Vereinbarungen über den Versorgungsausgleich, so sind insoweit die $\$ \$ 6$ und 8 des Versorgungsausgleichsgesetzes anzuwenden.

De acuerdo con esta norma, son objeto de regulación del Ehevertrag las relaciones patrimoniales entre los cónyuges, en especial, la anulación o modificación del régimen económico matrimonial. Además, como se desprende del apartado $2^{\circ}$ de la norma, también pueden ser objeto de regulación del Ehevertrag pactos sobre el llamado Versorgungsausgleich, una figura jurídica propia del derecho alemán que carece de equivalente en el derecho español ${ }^{7}$. De forma muy resumida, se puede decir que mediante el Versorgungsausgleich se trata de conseguir un reparto equitativo de los derechos a prestaciones de previsión social para el caso de invalidez y jubilación que los cónyuges hayan adquirido durante la duración del matrimonio. 
La doctrina jurídica alemana, a diferencia de la doctrina jurídica española, no suele distinguir entre un contenido típico y atípico de las capitulaciones matrimoniales, sino que se limita a señalar los cuatro puntos principales que se suelen regular en un Ehevertrag:

- ehelicher Güterstand

[el régimen económico matrimonial]

- nachehelicher Unterhalt

[las pensiones entre los cónyuges en caso de divorcio]

- Versorgungsausleich

[el reparto de los derechos a prestaciones de previsión social]

- erbrechtliche Regelungen

[eventuales pactos sucesorios]

Aparte de estos aspectos, se pueden incluir también otras estipulaciones, por ejemplo, sobre el ajuar doméstico (Hausrat) o la vivienda familiar (Ehewohnung). Finalmente, cabe destacar que tanto el derecho español como el derecho alemán prevén que las capitulaciones matrimoniales se pueden pactar antes de la celebración del matrimonio o durante el mismo (artículo $1326 \mathrm{CC}$, parágrafo 1408, apartado $1^{\circ} \mathrm{BGB}$ ).

A modo de resumen, en el siguiente cuadro, se comparan los fundamentos legales y el contenido de las capitulaciones matrimoniales y del Ehevertrag, respectivamente:

\section{CuAdro 1}

Fundamentos legales y contenido de las capitulaciones matrimoniales y del Ehevertrag

\begin{tabular}{|c|c|}
\hline España & Alemania \\
\hline $\begin{array}{l}\text { Fuente: Código Civil Español (CC) (TÍTULO III. } \\
\text { Del régimen económico matrimonial. } \\
\text { CAPÍTULO I-VI/ Artículos 1315-1444) }\end{array}$ & $\begin{array}{l}\text { Quelle: Bürgerliches Gesetzbuch (BGB) (Buch 4: } \\
\text { Familienrecht/ Abschnitt 1: Bürgerliche Ehe/Titel } \\
\text { 6: Eheliches Güterrecht (\$\$1363-1563) }\end{array}$ \\
\hline $\begin{array}{l}\text { Artículo } 1325 \text { CC } \\
\text { En capitulaciones matrimoniales podrán los } \\
\text { otorgantes estipular, modificar o sustituir el } \\
\text { régimen económico de su matrimonio o } \\
\text { cualesquiera otras disposiciones por razón del } \\
\text { mismo. }\end{array}$ & $\begin{array}{l}\text { \$1404 BGB } \\
\text { (1) Die Ehegatten können ihre güterrechtlichen } \\
\text { Verhältnisse durch Vertrag (Ehevertrag) regeln, } \\
\text { insbesondere auch nach der Eingehung der Ehe } \\
\text { den Güterstand aufheben oder ändern. } \\
\text { (2) Schließen die Ehegatten in einem Ehevertrag } \\
\text { Vereinbarungen über den Versorgungsausgleich, } \\
\text { so sind insoweit die } \$ \$ 6 \text { und } 8 \text { des } \\
\text { Versorgungsausgleichsgesetzes anzuwenden. }\end{array}$ \\
\hline $\begin{array}{l}\text { Contenido típico: } \\
\text { todas aquellas estipulaciones relativas al } \\
\text { establecimiento, la modificación o sustitución del } \\
\text { régimen económico matrimonial. } \\
\text { Contenido atípico: } \\
\text { cualesquiera otras disposiciones por razón del } \\
\text { matrimonio: } \\
\text { - las atribuciones no modificativas del régimen } \\
\text { económico matrimonial, en particular, las } \\
\text { donaciones por razón del matrimonio ya sea entre } \\
\text { los futuros cónyuges o por parte de terceros a } \\
\text { favor de los contrayentes; } \\
\text { - los negocios relativos a la sucesión de los } \\
\text { cónyuges; } \\
\text { - los negocios de derecho de familia no } \\
\text { patrimoniales; } \\
\text { - la constitución de determinados derechos reales; } \\
\text { - todos los actos y negocios que pueden y deben } \\
\text { constar en escritura pública. }\end{array}$ & $\begin{array}{l}\text { Contenido: } \\
\text { - la modificación o sustitución del régimen } \\
\text { económico matrimonial; } \\
\text { - las pensiones entre los cónyuges en caso de } \\
\text { divorcio (nachehelicher Unterhalt); } \\
\text { - el reparto de los derechos a prestaciones de } \\
\text { previsión social (Versorgungsausleich); } \\
\text { - eventuales pactos sucesorios (erbrechtliche } \\
\underline{\text { Regelungen). }}\end{array}$ \\
\hline
\end{tabular}




\subsubsection{Los tipos de regímenes económicos matrimoniales}

Hemos visto que el establecimiento o la modificación del régimen económico matrimonial constituyen el contenido principal tanto de las capitulaciones matrimoniales como del Ehevertrag. Por tanto, en la documentación específica sobre este documento es necesario estudiar este concepto de forma más detallada.

Como ya adelantamos, mientras dura un matrimonio, las relaciones económicas entre los esposos y entre estos y terceras personas están reguladas por su régimen matrimonial (ehelicher Güterstand). Ribó Durán (2005: 1211) define el régimen económico matrimonial como «el conjunto de normas que regula los intereses pecuniarios que surgen a consecuencia del matrimonio, refiriéndose a las relaciones patrimoniales de los cónyuges entre sí o a las que tengan con terceros». En este sentido, el régimen matrimonial determina principalmente qué efecto tiene el matrimonio sobre los bienes de los cónyuges, es decir, regula:

- los tipos de patrimonio que existen, nacen o se modifican al inicio del matrimonio, durante su existencia y en el momento de su disolución;

- la administración de estos patrimonios;

- a quién pertenecen los frutos del matrimonio;

- la responsabilidad por las deudas (Heintschel-Heinegg y Gerhardt 2006: 162).

Los regímenes económicos conyugales pueden clasificarse con arreglo a diferentes criterios. En función de su origen, es posible distinguir entre regímenes de carácter convencional (vertragliche Güterstände) y regímenes de carácter legal (gesetzliche Güterstände). Tanto en el derecho alemán como en el derecho español, los primeros se constituyen en virtud de un contrato celebrado por los cónyuges, las ya mencionadas capitulaciones matrimoniales, o Ehevertrag, en alemán. Los segundos derivan de la ley de manera directa, bien porque en determinadas circunstancias se impone obligatoriamente un régimen económico concreto, bien porque la norma legal funciona con carácter supletorio, esto es, rige en el caso de que los cónyuges no hayan establecido su régimen económico matrimonial por vía convencional.

Atendiendo al modo de organizar y distribuir la titularidad sobre las masas patrimoniales, cabe distinguir básicamente dos tipos de regímenes económicos del matrimonio: los que se basan en la comunidad de los bienes de los cónyuges, y aquellos en los que rige la separación de bienes.

En los regímenes de separación, no hay más patrimonios que los personales de cada uno de los consortes, los cuales son distintos e independientes entre sí. No existe patrimonio común. Los regímenes de comunidad, al contrario, se caracterizan precisamente por la existencia de un patrimonio común entre los cónyuges.

En la actualidad, tanto el CC como el BGB conocen tres regímenes económicos matrimoniales distintos:

Código Civil ${ }^{8}$ :

- régimen de gananciales;

- régimen de separación de bienes;

- régimen de participación en las ganancias.

Bürgerliches Gesetzbuch:

- Zugewinngemeinschaft;

- Gütertrennung;

- Allgemeine Gütergemeinschaft. 
A continuación, se estudiarán con más detalle los diferentes tipos de regímenes económicos matrimoniales. En lo que se refiere al régimen de separación de bienes y la Gütertrennung, así como al régimen de participación y la Zugewinngemeinschaft, nos permitimos tratarlos conjuntamente, ya que la idea básica que les subyace es la misma en el CC y en el BGB, aunque cada régimen puede presentar características o particularidades propias en sendos ordenamientos jurídicos, las cuales se deben consultar en caso de que sea necesario profundizar en ellas. El régimen de gananciales, por el contrario, en la actualidad solo existe en el derecho español y el régimen de la Allgemeine Gütergemeinschaft, solo en el derecho alemán.

\subsubsection{Separación de bienes y Gütertrennung}

El régimen económico matrimonial de separación de bienes se caracteriza por la existencia de solo dos masas patrimoniales dentro del matrimonio, las privativas de cada cónyuge. La idea central es la independencia económica absoluta de los consortes, de modo que cada uno de ellos conserva el dominio, la administración y el usufructo sobre su propio patrimonio. En este sentido, pertenecen a cada cónyuge los bienes que tuviera antes de la celebración del matrimonio, así como los que adquiera durante el mismo (De la Rocha García 1999: 161). No se crea un patrimonio común entre los cónyuges por razón del matrimonio.

En el CC, el régimen de separación de bienes está previsto en los artículos 1435 a 1444; el BGB lo regula en el parágrafo 1414. Tanto en el CC como en el BGB se establece ese régimen como régimen voluntario o convencional, de una parte, y legal supletorio de segundo grado, de otra. Es decir, rige si los cónyuges así lo convienen en capitulaciones matrimoniales o si los consortes han pactado el rechazo al régimen económico legal sin determinar otro régimen económico para su matrimonio.

\subsubsection{Régimen de participación en las ganancias y Zugewinngemeinschaft}

La Zugewinngemeinschaft surge del derecho alemán, donde se instaura como régimen legal en 1958, es decir, es el régimen que rige por defecto si los cónyuges no han convenido otro régimen distinto en capitulaciones matrimoniales, por lo que tiene una gran relevancia práctica en Alemania. Se encuentra regulado en los parágrafos 1363 a 1390 BGB.

Sucesivamente, este régimen ha sido acogido también por otros ordenamientos jurídicos europeos. Así, en 1981, se introdujo como régimen convencional en el derecho español bajo el nombre régimen de participación en las ganancias, donde es regulado en los artículos 1411 y siguientes CC (Díez-Picazo y Gullón 1998: 238).

El régimen de participación en las ganancias o Zugewinngemeinschaft es un régimen mixto, ya que presenta rasgos del régimen de separación de bienes y rasgos del régimen de comunidad de bienes. Al igual que en el caso de la separación de bienes, en el régimen de participación solo existen dos masas patrimoniales, los patrimonios privativos de cada cónyuge. Con la celebración del matrimonio no se crea por disposición de la ley un patrimonio conyugal común a los esposos. Cada cónyuge conserva la administración, el disfrute y la libre disposición de los bienes que le pertenecen cuando comienza el régimen de participación en las ganancias, así como de los que adquiera durante el mismo por cualquier título (principalmente: por compra, donación o herencia). Lo que distingue este régimen del régimen de separación de bienes es que cada cónyuge adquiere un derecho a participar en las ganan- 
cias obtenidas por su consorte durante el tiempo en que el régimen de participación haya estado vigente. No obstante, este derecho a participar en las ganancias no se manifiesta durante el matrimonio, sino solamente al disolverse este, es decir, en caso de divorcio ${ }^{9}$, originándose un crédito de participación -Zugewinnausgleichsanspruch, en alemán- a favor del cónyuge económicamente más débil que durante el matrimonio haya obtenido menos ganancias (Zugewinn) (artículo 1411 CC; parágrafo 1378 BGB) (De la Rocha García 1999: 152).

Cabe destacar que, mientras que en Alemania, la Zugewinngemeinschaft, al ser el régimen legal, es muy importante en la práctica, en España, solo un número muy escaso de matrimonios se rige por el régimen de participación en las ganancias (Lasarte 2007: 294).

\subsubsection{Régimen de la sociedad de gananciales}

El Código Civil establece la sociedad de gananciales como régimen económico conyugal legal (artículo 1316 CC) y la regula en los artículos 1344 a 1410 (Díez-Picazo y Gullón 1998: 175). La idea dominante de este régimen es que el incremento patrimonial es obra de la colaboración conyugal, por lo que los bienes adquiridos durante el matrimonio se hacen comunes, formando el denominado patrimonio ganancial. Junto al patrimonio común de los cónyuges, pueden existir también bienes propios de cada uno de ellos, los llamados patrimonios privativos. Por tanto, en el régimen de gananciales se deben distinguir tres masas patrimoniales: el patrimonio privativo de la esposa, el patrimonio privativo del esposo y el patrimonio ganancial (Simó Santonja 2005: 220, 226).

Queremos hacer hincapié en que no se debe confundir el régimen de gananciales con el régimen matrimonial de participación en las ganancias o Zugewinngemeinschaft, ya que se trata de dos figuras jurídicas diferentes. Mientras que el régimen de gananciales tiene «efectos reales inmediatos» (Díez-Picazo y Gullón 1998: 238), es decir, las ganancias adquiridas por cualquiera de los cónyuges durante el matrimonio se convierten en patrimonio común, en el régimen de participación, las ganancias continúan siendo individuales, no se crea un patrimonio común. Solamente en el momento de la disolución del régimen de participación, por ejemplo, por divorcio, el cónyuge cuyo patrimonio haya visto un incremento menor durante el matrimonio tiene un derecho de crédito frente al otro.

\subsubsection{Allgemeine Gütergemeinschaft}

La Allgemeine Gütergemeinschaft constituye un régimen convencional en el derecho alemán y se regula en los parágrafos 1415 a 1518 BGB. El rasgo más característico de ese régimen es que, por razón del matrimonio, se constituye por disposición de la ley un patrimonio conyugal común, llamado Gesamtgut, parágrafo 1416, apartado 1 BGB. El patrimonio común se compone de los bienes que tenga cada uno de los cónyuges en el momento de la celebración del matrimonio y de los bienes que adquiera cada uno en el futuro.

No obstante, aunque en principio se ponen en común tanto los bienes presentes como futuros de los cónyuges, existen algunos bienes que quedan excluidos del patrimonio común. Se trata del denominado Sondergut (patrimonio privativo) y del Vorbehaltsgut (patrimonio reservado). Por tanto, en el caso de la comunidad general de bienes, pueden existir hasta cinco masas patrimoniales diferentes, a saber, el 
patrimonio común, el patrimonio privativo de la esposa, el patrimonio privativo del esposo, el patrimonio reservado de la esposa y el patrimonio reservado del esposo. Cabe apuntar que, en la actualidad, la relevancia práctica de este régimen económico matrimonial es casi nula ya que apenas se elige como régimen económico matrimonial ${ }^{10}$.

\subsubsection{Comparación de los regímenes económicos matrimoniales}

Comparando los regímenes económicos matrimoniales previstos en el CC y en el BGB vemos que ambos códigos conocen la separación de bienes o Gütertrennung y la participación en las ganancias o Zugewinngemeinschaft, y los principios que subyacen a estos regímenes en ambos ordenamientos jurídicos son comunes. Por tanto, en los casos de traducción que hemos planteado en la Introducción del presente estudio (traducción de unas capitulaciones matrimoniales al alemán o de un Ehevertrag al español para acreditar en casos de divorcio o de herencia el régimen económico al que está sujeto un matrimonio mixto), podrían funcionar como equivalentes de traducción ${ }^{11}$.

La Allgemeine Gütergemeinschaft, no obstante, es propia del sistema jurídico alemán y el régimen de gananciales, del sistema jurídico español. En cuanto a este último, cabe apuntar que su equivalente en el derecho alemán podría ser la llamada Errungenschaftsgemeinschaft, un régimen económico previsto por el BGB hasta 1958. En el caso de la Errungenschaftsgemeinschaft, se ponía en común el patrimonio que los cónyuges adquiriesen durante la duración del matrimonio, mientras que cada cónyuge mantenía la titularidad sobre el patrimonio del que disponía con anterioridad a la celebración del matrimonio. En este sentido, puede afirmarse que la Errungenschaftsgemeinschaft presentaba semejanzas sustanciales con el régimen español de la sociedad de gananciales (Bustos Moreno 2001).

A modo de resumen, en el siguiente cuadro, se enumeran los regímenes previstos en el CC y el BGB, respectivamente, se citan las normativas correspondientes y se proponen las posibles equivalencias de traducción a las que hemos llegado como resultado del estudio jurídico realizado:

\section{CUADRO 2}

Regímenes económicos matrimoniales previstos en el CC y su posible equivalencia en el Derecho alemán

\begin{tabular}{|l|l|}
\hline $\begin{array}{l}\text { Regímenes económicos matrimoniales } \\
\text { previstos en el Código Civil }\end{array}$ & Posible equivalencia de traducción \\
\hline $\begin{array}{l}\text { sociedad de gananciales } \\
\text { artículos 1344-1410 CC }\end{array}$ & $\begin{array}{l}\text { Errungenschaftsgemeinschaft } \\
\text { (régimen previsto en el BGB hasta 1958; en la } \\
\text { actualidad desconocido en el derecho alemán) }\end{array}$ \\
\hline $\begin{array}{l}\text { participación en las ganancias } \\
\text { artículos 1411-1434 CC }\end{array}$ & $\begin{array}{l}\text { Zugewinngemeinschaft } \\
\text { (regulada en los \$\$ 1363-1390 BGB) }\end{array}$ \\
\hline $\begin{array}{l}\text { separación de bienes } \\
\text { artículos 1435-1444 CC }\end{array}$ & $\begin{array}{l}\text { Gütertrennung } \\
\text { (regulada en el \$1414 BGB) }\end{array}$ \\
\hline
\end{tabular}


CUADRO 3

Regímenes económicos matrimoniales previstos en el BGB y su posible equivalencia en el Derecho español

\begin{tabular}{|l|l|}
\hline $\begin{array}{l}\text { Regímenes económicos matrimoniales } \\
\text { previstos en el Bürgerliches Gesetzbuch }\end{array}$ & Posible equivalencia de traducción \\
\hline Zugewinngemeinschaft & $\begin{array}{l}\text { participación en las ganancias } \\
\text { (regulada en los artículos 1411-1434 CC) }\end{array}$ \\
\hline$\$ \$ 1363-1390$ BGB & $\begin{array}{l}\text { separación de bienes } \\
\text { (regulada en los artículos 1435-1444 CC) }\end{array}$ \\
\hline Gütertrennung & $\begin{array}{l}\text { comunidad general de bienes } \\
\text { (régimen no previsto en el CC) }\end{array}$ \\
\hline$\$ 1414$ BGB & Allgemeine Gütergemeinschaft \\
$\$ \$ 1415-1518$ BGB &
\end{tabular}

Como muestra el ejemplo de los regímenes económicos matrimoniales, la aproximación al texto en la fase preparatoria mediante la documentación temática específica permite la extracción y definición de términos en español y alemán que constituyen conceptos básicos en este campo, lo que prepara la base para el establecimiento de posibles equivalencias traductoras.

\section{Estudio textual comparado}

Al tratarse, como veremos, de textos con partes estandarizadas muy marcadas, una buena base para desarrollar un estudio comparado de los textos es la división de estos en secciones y la descripción de las características de cada sección en lo que concierne al contenido y a los elementos lingüísticos que la conforman ${ }^{12}$.

A la hora de estudiar la estructura textual de las capitulaciones matrimoniales hay que tener en cuenta una particularidad que se da en numerosos textos del ámbito del derecho ${ }^{13}$ : la redacción de las capitulaciones matrimoniales no es libre, sino que existe una normativa que la regula. Por tanto, a la hora de identificar las secciones textuales, nos hemos basado tanto en las muestras textuales que constituyen nuestro corpus como en la legislación correspondiente.

En primer lugar, cabe constatar que las capitulaciones matrimoniales y el Ehevertrag se enmarcan dentro de la macrocategoría documento notarial, es decir, para su validez se exige que se otorguen ante notario. Tanto el derecho español como el derecho alemán conocen diferentes clases de documentos notariales ${ }^{14}$ para las que se establecen también diferentes requisitos formales. En el caso del derecho español, las capitulaciones matrimoniales deben constar en lo que se conoce como escritura pública (regulada en los artículos 156-196 del Reglamento Notarial, en lo sucesivo RN); en el caso del Ehevertrag, este ha de formalizarse en una Niederschrift über die Verhandlung -también denominado notarielle Niederschrift o Protokoll- (regulada en los parágrafos 8-35 del Beurkundungsgesetz, en lo sucesivo BeurkG). 
CUADRO 4

La forma de las capitulaciones matrimoniales y del Ehevertrag

\begin{tabular}{|l|l|}
\hline España & Alemania \\
\hline Escritura pública & Niederschrift über die Verhandlung \\
$\begin{array}{l}\text { Artículo 1327 CC } \\
\text { Para su validez, las capitulaciones habrán de } \\
\text { constar en escritura pública. }\end{array}$ & $\begin{array}{l}\text { \$1410 BGB } \\
\text { Der Ehevertrag muss bei gleichzeitiger } \\
\text { Anwesenheit beider Teile zur Niederschrift } \\
\text { eines Notars geschlossen werden }\end{array}$ \\
\hline $\begin{array}{l}\text { Requisitos formales: artículos 156-196 del } \\
\text { Reglamento Notarial }\end{array}$ & $\begin{array}{l}\text { Requisitos formales: } \$ \$ 8 \text {-35 del } \\
\text { Beurkundungsgesetz }\end{array}$ \\
\hline
\end{tabular}

\subsection{Estructura textual de las capitulaciones matrimoniales españolas}

Teniendo en cuenta la legislación citada y las muestras textuales, hemos podido identificar las siguientes secciones en las capitulaciones matrimoniales españolas:

- encabezamiento ${ }^{15 ;}$

- comparecencia;

- exposición de hechos;

- estipulaciones:

- régimen económico matrimonial;

- otras disposiciones;

- inscripción en los registros correspondientes;

- protección de datos;

- otorgamiento;

- autorización.

\subsubsection{Encabezamiento}

En cuanto a la primera sección, el encabezamiento, su función consiste en permitir la identificación y el archivo ordenado del documento. En este sentido, se consignan en él los siguientes datos:

- número de protocolo: suele figurar en la primera línea de la escritura. Normalmente, se pone en letra, pero también se puede poner en letra y con el número entre paréntesis;

- lugar de otorgamiento: normalmente, la residencia del notario;

- fecha de otorgamiento: debe constar en letra; se han de expresar el día, el mes y el año;

- notario autorizante: han de constar su nombre y apellidos, el lugar de residencia y el colegio notarial al que pertenece;

- calificación del documento: se incluye dentro del encabezamiento la calificación del acto o contrato con el nombre conocido que tenga en derecho, en nuestro caso, capitulaciones matrimoniales.

\section{CAPITULACIONES MATRIMONIALES ${ }^{16}$ NUMERO: SETECIENTOS OCHENTA Y CINCO}

En Salamanca, a dieciséis de mayo del año dos mil siete.

Ante mí, JOSÉ JUAN PEDREIRA CALLEJA, Notario del Ilustre colegio de Valladolid, con residencia en Salamanca, [...] 


\subsubsection{Comparecencia}

Una vez consignados los datos necesarios para la identificación y el archivo ordenado del documento, es necesario determinar e identificar a las personas que se encuentren presentes ante el notario para formalizar las capitulaciones matrimoniales, lo que nos lleva a la parte denominada comparecencia. En ella, se hacen constar los siguientes datos:

- circunstancias personales de los cónyuges o futuros cónyuges: nombre y apellidos, estado civil, mayoría de edad, nacionalidad cuando se trate de extranjeros, domicilio, expresando calle y número, municipio, código postal y provincia, documento nacional de identidad;

- la afirmación a juicio del notario de que los otorgantes tienen la capacidad legal necesaria para otorgar las capitulaciones matrimoniales;

- la constatación de si la intervención de los otorgantes se produce en nombre propio o en nombre de otro;

- la profesión o cualquier otro dato personal (opcional).

\section{COMPARECEN}

DON CARLOS $\mathrm{XX}^{17}$, mayor de edad, soltero, con domicilio en Madrid, en XX; y con D.N.I. número XX

Y DOÑA ELENA XX, mayor de edad, soltera, con domicilio en Madrid, XX

INTERVIENEN en su propio nombre y derecho.

Tienen, a mi juicio, la capacidad legal necesaria para otorgar esta escritura de capitulaciones matrimoniales [...]

\subsubsection{Exposición de hechos}

A la comparecencia sigue la exposición de hechos, que está constituida fundamentalmente por declaraciones de carácter no contractual que son efectuadas por los cónyuges en contemplación de las capitulaciones matrimoniales que pretenden otorgar. Pueden ser datos acerca de la fecha prevista para la celebración del matrimonio, o la fecha en la que los cónyuges contrajeron matrimonio si las capitulaciones se otorgan con posterioridad a este y, en el segundo caso, datos acerca del régimen económico vigente hasta ahora.

\section{-EXPONEN-:}

I. Que contrajeron matrimonio en San Antonio de Estoril-Carcais [sic] (Portugal), el día 14 de abril de 1984, que se inscribió en el Registro Civil del consulado General de España en Lisboa, al tomo 33, página 173.

II. Que su matrimonio se ha venido rigiendo, desde esa fecha, por el sistema de gananciales, de conformidad con lo previsto en el artículo 1.316 del Código Civil, puesto que hasta el día de hoy no se ha otorgado contrato alguno regulador de dicha sociedad conyugal.

III. Que haciendo uso los comparecientes de la facultad que les concede el artículo 1.325 del Código Civil, han decidido de mutuo acuerdo, modificar el régimen económico de su matrimonio, estableciendo el sistema de separación absoluta de bienes, lo que llevan a efecto mediante la presente escritura y con sujeción a las siguientes

\section{-CLÁUSULAS-}




\subsubsection{Estipulaciones}

En cuanto a la siguiente parte, denominada estipulaciones, es la parte contractual ya que en ella se establecen las normas de carácter patrimonial aplicables al matrimonio de los otorgantes, es decir, se fija, sobre todo, el régimen matrimonial.

\section{OTORGAN:}

Que establecen como régimen económico de su futuro matrimonio el de SEPARACIÓN ABSOLUTA DE BIENES, que se regirá por lo dispuesto en los artículos 1.435 a 1.444 del Código Civil Español [...]

PRIMERO.- Cada cónyuge hace suyos con independencia del otro los frutos de sus bienes propios, si bien con la obligación de contribuir al sostenimiento de las cargas del matrimonio proporcionalmente a sus respectivos recursos económicos.

En ocasiones, puede ser necesario que las relaciones patrimoniales se determinen con más detalle, por ejemplo, cuando se liquida un régimen económico matrimonial y se establece otro. En ese caso, las capitulaciones matrimoniales suelen comprender un listado exacto de los bienes que están en juego.

\section{-CLÁUSULAS-}

PRIMERA.- A partir del día de hoy se entiende disuelta la sociedad ganancial del matrimonio formado por los señores comparecientes, que se entenderá sometido al régimen de separación absoluta de bienes [...]

Cuarta.- En aplicación de las cláusulas anteriores, los señores comparecientes convienen la liquidación de la sociedad de gananciales constituida por ambos, y a tal efecto, hacen constar que los bienes de carácter ganancial son los siguientes:

1) Urbana. Finca número 35. Vivienda en Planta sexta número 606. Situada en la planta sexta, que es la séptima sobre rasante, de la casa número XX de la Calle XX, de Madrid.

Las estipulaciones suelen contener también una referencia a la inscripción de las capitulaciones matrimoniales en los registros correspondientes (registro civil, registro de la propiedad, registro mercantil).

CUARTO.- Los comparecientes solicitan del Encargado del Registro Civil que haga constar al margen de la inscripción del matrimonio la modificación de su régimen económico matrimonial, pactado en esta escritura.

Como último punto, en las estipulaciones se suele hacer referencia a la inclusión de los datos de los otorgantes en los ficheros automatizados de la notaría.

\section{PROTECCIÓN DE DATOS DE CARÁCTER PERSONAL.-}

De acuerdo con lo establecido en la Ley Orgánica 15/1999, los comparecientes quedan informados y aceptan la incorporación de sus datos a los ficheros automatizados existentes en al Notaría, que se conservarán en la misma con carácter confidencial, sin perjuicio de las remisiones de obligado cumplimiento [...]

\subsubsection{Otorgamiento}

Una vez convenidos los pactos entre los cónyuges, estos han de prestar su consentimiento al contenido de las capitulaciones matrimoniales, lo que da lugar a la sección conocida como otorgamiento. A modo de aclaración terminológica, queremos destacar que quienes otorgan las capitulaciones matrimoniales son los cónyuges o futuros cónyuges, llamados también otorgantes. El notario por su parte, no otorga, sino que autoriza la escritura ${ }^{18}$. En sentido amplio, el otorgamiento se refiere al proceso esta- 
blecido y regulado por la ley que tiene por objeto la creación y el nacimiento de un instrumento público. Desde este punto de vista, el otorgamiento se inicia cuando los interesados comparecen ante el notario y finaliza con la autorización por este del instrumento público. En un sentido más estricto y técnico, el otorgamiento equivale a la prestación del consentimiento por los interesados al contenido del instrumento público y su constancia en el mismo (Jiménez y Leyda 2008: 251).

En el acto del otorgamiento, el notario ha de leer a las partes la escritura íntegra o permitirles que la lean, a su elección, antes de que la firmen. Asimismo, para asegurar que los otorgantes estén plenamente conscientes del alcance y de los efectos que pueden derivarse del otorgamiento del documento público, el notario hace de palabra las reservas y advertencias legales pertinentes. De todo ello se deja constancia en el documento:

Así lo otorgan los comparecientes a los que hago las reservas y advertencias legales y les leo esta escritura, previa su renuncia al derecho para leer por sí, del que les enteré, y encontrándola conforme, ratifican su contenido y la firman conmigo.

\subsubsection{Autorización}

El documento se cierra con la llamada autorización, mediante la que el notario asume la autoría del documento y verifica y declara formalmente que cumple todos los requisitos para su eficacia como tal (Jiménez Clar y Leyda Ern 2008: 270). La autorización se refiere al contenido íntegro del instrumento público, en concreto, a la identidad de los otorgantes, su capacidad y legitimación, al hecho de que el consentimiento ha sido libremente prestado y de que el otorgamiento se adecua a la legalidad. La autorización precisa necesariamente la firma del notario, que estará integrada por el signo, la firma y rúbrica acompañados del sello.

De identificar a los comparecientes por sus documentos de identidad antes reseñados en la forma legal y de todo lo demás pertinente, consignado en este instrumento público, extendido en tres folios de papel timbrado, de uso exclusivo notarial, serie 6T, números 5849067, 5849068, y el presente, yo, el Notario, doy fe.

Están las firmas de las personas comparecientes. Signado: I. Figaredo de la Mora. Rubricado y sellado.

Las secciones otorgamiento y autorización también pueden aparecer como una única sección.

\section{OTORGAMIENTO Y AUTORIZACIÓN}

Les permito la lectura de esta escritura por su elección, después de advertidos de la opción del artículo 193 del Reglamento Notarial, previa explicación por mí, el notario, a petición de los interesados, de los extremos relevantes del documento. Hacen constar su consentimiento y la firman conmigo el Notario, que doy fe de haberles identificado por sus documentos de identidad que me han exhibido y antes reseñados y, en lo pertinente, de cuanto se expresa en este instrumento público que va extendido sobre tres folios del timbre del Estado, de uso exclusivo para documentos notariales, serie $7 \mathrm{U}$, números 8210371, 8210372 y 8210373.

Siguen las firmas de los comparecientes.

Signado: José Juan Pedreira Calleja. Rubricados. Sellado. 


\subsection{Estructura textual de las capitulaciones matrimoniales alemanas}

En cuanto a la estructura textual de las capitulaciones matrimoniales alemanas, en los parágrafos 8 y siguientes BeurkG se establece el contenido que debe tener una Niederschrift über Willenserklärungen, que, como ya hemos visto, es la forma en la que ha de constar este documento (Faßbender, Grauel et al. 2010: 107, 108).

El estudio de la documentación jurídica y de las muestras textuales da como resultado que las capitulaciones matrimoniales alemanas suelen constar de las siguientes secciones ${ }^{19}$ :

- Urkundseingang [encabezamiento];

- Bezeichnung der Beteiligten [comparecencia];

- Sachstand [exposición de hechos];

- Erklärungen der Beteiligten [estipulaciones]:

- Güterstand [régimen económico];

- Versorgungsausgleich [reparto de los derechos a prestaciones de previsión social];

- nachehelicher Unterhalt [pensión en caso de divorcio];

- erbrechtliche Regelungen [pactos sucesorios];

- Belehrungen [reservas y advertencias legales];

- Schlussbestimmungen [disposiciones finales];

- salvatorische Klausel [cláusula salvatoria];

- Kosten [costes];

- Ausfertigungen und Abschriften [copias];

- Schlussvermerk und Unterschriften [otorgamiento y autorización].

\subsubsection{Encabezamiento (Urkundseingang)}

Muy similar al encabezamiento de los documentos españoles, en el Urkundseingang de las capitulaciones matrimoniales alemanas se consignan los siguientes datos (Dannenberg y Baumgärtner 2005: 35 y ss.):

- número que tiene asignado un determinado documento en el índice del protocolo notarial (Urkundenrolle). Suele figurar en la primera línea de la escritura;

- lugar y fecha de otorgamiento (Bezeichnung des Ortes und des Tags der Verhandlung): Se indica dónde y cuándo se ha otorgado la escritura pública, normalmente, la residencia del notario;

- identificación del notario (Bezeichnung des Notars): el encabezamiento de la Niederschrift debe contener los datos referentes al notario que la autorice. Han de constar su nombre y apellidos y el lugar de residencia (Amtssitz);

- calificación del documento: se incluye dentro del encabezamiento la calificación del acto o contrato con el nombre conocido que tenga en derecho, en nuestro caso, Ehevertrag.

Urkundenrolle Nr. 1/1985

\section{Ehevertrag}

Stuttgart

Geschehen am 9. Januar 1985

(neunter Januar neunzehnhundertfünfundachtzig)

Vor dem unterzeichneten Notar Siegfried Koehler mit dem Amtssitz in Stuttgart erschienen heute gleichzeitig im Amtszimmer in 7000 Stuttgart 80 (Möhringen), Tangegartenstraße 5: 


\title{
3.2.2. Comparecencia (Bezeichnung der Beteiligten)
}

A continuación, al igual que en los documentos españoles, se identifica a los otorgantes (Bezeichnung der Beteiligten), por lo que hemos denominado esta parte comparecencia. Se indican sus nombres y apellidos, apellido antes del matrimonio, en su caso, fecha de nacimiento, calle y localidad donde residen. También se puede incluir la profesión.

El notario ha de indicar cómo se ha cerciorado de la identidad de las partes, por ejemplo, a través de la presentación de los documentos nacionales de identidad, o porque los conoce personalmente.

\author{
1. Frau Barbara XXX \\ geboren am 14.11.19XX \\ wohnhaft in Weimar, XX-Str. XX \\ 2. Herr Frank XX \\ geboren am 23.07.XX \\ wohnhaft in Weimar, XX-Str. XX \\ Beide mir, Notar, persönlich bekannt.
}

\subsubsection{Exposición de hechos (Sachstand)}

A la comparecencia siguen las declaraciones de los otorgantes. Al igual que en el documento español, se distingue entre, por un lado, la exposición de hechos (Sachstand) y las estipulaciones, es decir, los pactos convenidos entre los otorgantes, por otro (Erklärungen der Beteiligten).

Similar a la exposición de hechos en el documento español, la sección de Sachstand está constituida por declaraciones de carácter no contractual que las partes efectúan en contemplación de las capitulaciones matrimoniales que van a otorgar. Puede contener datos, por ejemplo, acerca de la celebración del matrimonio, hijos existentes, nacionalidad, profesión, etc.

Auf Ersuchen der Erschienenen und aufgrund ihrer bei gleichzeitiger Anwesenheit vor mir abgegebenen Erklärungen beurkunde ich folgenden

\section{Ehevertrag:}

I.

\section{Sachstand}

Wir haben am 22.06.2001 in Würzburg geheiratet. Zu diesem Zeitpunkt hatten wir beide unseren ständigen Aufenthalt in Deutschland.

Aus unserer Ehe ist bislang ein Kind hervorgegangen, das am Leben ist, nämlich Philipp, geb. am 04.XX.XX

Wir haben bisher keine ehevertraglichen Vereinbarungen getroffen

Wir besitzen beide die deutsche Staatsangehörigkeit und haben kein Auslandsvermögen. Wir sind beide berufstätig und beabsichtigen, dies auch weiterhin zu sein, also auch während der Dauer unserer Ehe [...].

\subsubsection{Estipulaciones (Erklärungen der Beteiligten)}

A la exposición de hechos siguen los acuerdos vinculantes convenidos entre los otorgantes, que son equiparables a lo que en español se conoce como estipulaciones. Con frecuencia, esta sección se introduce mediante una fórmula como

Dies vorausgeschickt vereinbaren wir was folgt. 
Las estipulaciones se pueden dividir en varias subsecciones, dependiendo de las materias que se regulan en ellas. Las secciones más frecuentes son: régimen económico (Güterstand), reparto de los derechos a prestaciones de previsión social (Versorgungsausgleich), pensión en caso de divorcio (nachehelicher Unterhalt) y pactos sucesorios (erbrechtliche Regelungen).

En la sección Güterstand se establece el régimen económico que se aplicará al matrimonio.

II.

\section{Güterstand}

Für unsere Ehe belassen wir es beim gesetzlichen Güterstand der Zugewinngemeinschaft. Wir modifizieren aber den gesetzlichen Güterstand für unsere zukünftige Ehe wie folgt: $[\ldots]$

Wir schließen das Zustimmungserfordernis eines jeden Ehegatten nach $\$ \$ 1365$ und 1369 BGB aus, falls ein Ehegatte über sein Vermögen im ganzen oder über wesentliche Bestandteile seines Vermögens oder über Gegenstände des gemeinschaftlichen Haushalts verfügt.

En la sección Versorgungsausgleich se suele estipular que, en caso de divorcio, se excluirá el reparto de los derechos a prestaciones de previsión social.

III.

1. Ausschluss

\section{Versorgungsausgleich}

Wir schließen hiermit gem. $\$ 1408$ a Abs. 2 BGB die Durchführung des Versorgungsausgleichs für die gesamte Ehezeit aus.

En la parte Nachehelicher Unterhalt se pueden regular eventuales derechos a pensión entre los cónyuges en caso de divorcio.

\section{IV.}

\section{Nachehelicher Unterhalt}

Bei der gesetzlichen Regelung des nachehelichen Unterhalts soll es grundsätzlich verbleiben. Jedoch begrenzen wir hiermit die Höhe etwaiger Ansprüche eines geschiedenen Ehegatten gegen den anderen auf nachehelichen Unterhalt wie folgt: [...]

En la sección erbrechtliche Regelungen, los otorgantes tienen la posibilidad de establecer pactos sucesorios.

\section{V.}

\section{Erbrechtliche Regelungen}

Der Notar hat uns über das gesetzliche Erb- und Pflichtteilsrecht belehrt. Hierzu sollen in der heutigen Urkunde keine Regelungen getroffen werden, insbesondere soll kein Erb und bzw. Pflichtteilsverzicht vereinbart werden.

A las estipulaciones patrimoniales sigue la sección Belehrungen, en la que se deja constancia de que el notario ha advertido a los otorgantes de las consecuencias jurídicas de los pactos convenidos:

VI.

\section{Belehrungen}

Wir wurden vom amtierenden Notar darüber belehrt, dass durch die Vereinbarung nach Ziffer II ein Zugewinnausgleich bei Auflösung der Ehe durch Scheidung nicht stattfindet, keiner von uns den Beschränkungen der $\$ \$ 1365,1369$ BGB unterworfen ist und somit 
jeder Ehegatte über sein Vermögen frei verfügen kann, eine Haftungsbeschränkung gegenüber Gläubigern nicht eintritt.

Wir wurden vom Notar weiter über die rechtliche und wirtschaftliche Tragweite des Unterhaltsverzichts und des Ausschlusses des Versorgungsausgleiches belehrt.

En las disposiciones finales (Schlussbestimmungen) se suele incluir una cláusula salvatoria en la que se establece que la ineficacia de una de las cláusulas del documento no afecta a la validez del mismo. Además, se suele disponer quién corre con los costes del otorgamiento del documento notarial y se hace mención a las copias del documento matriz que reciben los otorgantes.

VII.

1. Salvatorische Klausel

\section{Schlussbestimmungen}

Sollte eine Vereinbarung dieses Vertrages unwirksam sein oder werden, so bleibt die Wirksamkeit der übrigen Bestimmungen davon unberührt. Die unwirksame Bestimmung ist nach Möglichkeit durch eine wirtschaftlich gleichwertige zu ersetzen.

2. Kosten

Die Kosten dieser Urkunde tragen wir je zur Hälfte.

3. Ausfertigungen und Abschriften

Von dieser Urkunde bitte wir jedem von uns eine Ausfertigung zu erteilen.

\subsubsection{Otorgamiento y autorización (Schlussvermerk und Unterschriften)}

Al final del documento, el notario debe hacer constar que este ha sido leído a las partes, que las partes se han declarado de acuerdo con él y que lo han firmado (Huhn y Schuckmann 2003: 205). Esta parte se conoce como Schlussvermerk und Unterschriften y se corresponde con la sección de otorgamiento y autorización en los documentos españoles.
Vorgelesen vom Notar von den Beteiligten genehmigt und eigenhändig unterschrieben.

\subsection{Comparación de los esquemas textuales}

Comparando los esquemas textuales de las capitulaciones matrimoniales españolas y alemanas, vemos que existe un alto grado de similitud, estando presentes en ambos documentos las secciones básicas que componen la macroestructura que caracteriza esta clase textual (encabezamiento, comparecencia, exposición de hechos, estipulaciones, otorgamiento y autorización). En lo que sí se observan diferencias notables es en el contenido de las subsecciones de la sección estipulaciones, hecho que se debe a que cada documento esté enraizado en una cultura jurídica propia, que es la que determina el contenido específico del texto. 
CUADRO 5

Secciones de las capitulaciones matrimoniales y del Ehevertrag

\begin{tabular}{|c|c|}
\hline Secciones de las capitulaciones matrimoniales & Secciones del Ehevertrag \\
\hline $\begin{array}{l}\text { - encabezamiento; } \\
\text { - comparecencia; } \\
\text { - exposición de hechos; } \\
\text { - estipulaciones: } \\
\text { - régimen económico; } \\
\text { - otras disposiciones; } \\
\text { - inscripción en los registros } \\
\text { correspondientes; } \\
\text { - protección de datos; } \\
\text { - otorgamiento; } \\
\text { - autorización. }\end{array}$ & 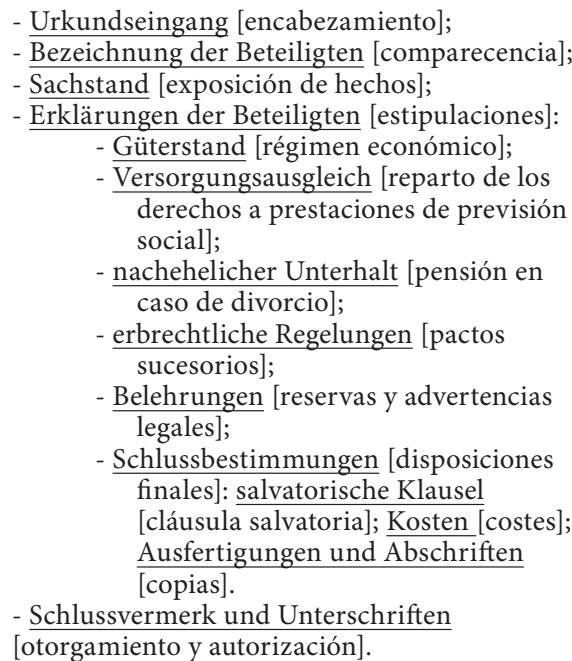 \\
\hline
\end{tabular}

Como hemos visto, cada una de estas secciones ofrece una serie de elementos microestructurales que son característicos de esta clase de textos.

CuAdro 6

Elementos microestructurales de las capitulaciones matrimoniales y del Ehevertrag

\begin{tabular}{|c|c|}
\hline Capitulaciones matrimoniales & Ehevertrag \\
\hline \multicolumn{2}{|c|}{ Encabezamiento } \\
\hline $\begin{array}{l}\text { CAPITULACIONES MATRIMONIALES } \\
\text { NUMERO: SETECIENTOS OCHENTA Y } \\
\text { CINCO } \\
\text { En Salamanca, a dieciséis de mayo del año dos } \\
\text { mil siete. } \\
\text { Ante mí, JOSÉ JUAN PEDREIRA CALLEJA, } \\
\text { Notario del Ilustre colegio de Valladolid, con } \\
\text { residencia en Salamanca, [...] }\end{array}$ & $\begin{array}{l}\text { Ehevertrag } \\
\text { Urkundenrolle Nr. 1/1985 } \\
\text { Stuttgart } \\
\text { Geschehen am 9. Januar } 1985 \\
\text { (neunter Januar } \\
\text { neunzehnhundertfünfundachtzig) } \\
\text { Vor dem unterzeichneten Notar Siegfried } \\
\text { Koehler mit dem Amtssitz in Stuttgart } \\
\text { erschienen heute gleichzeitig im Amtszimmer } \\
\text { in } 7000 \text { Stuttgart } 80 \text { (Möhringen), } \\
\text { Tangegartenstraße 5: [...] }\end{array}$ \\
\hline \multicolumn{2}{|c|}{ Comparecencia } \\
\hline $\begin{array}{l}\text { COMPARECEN: } \\
\text { DON CARLOS XX, mayor de edad, soltero, con } \\
\text { domicilio en Madrid, en XX; y con D.N.I. } \\
\text { número XX } \\
\text { Y DOÑA ELENA XX, mayor de edad, soltera, } \\
\text { con domicilio en Madrid, XX } \\
\text { INTERVIENEN en su propio nombre y } \\
\text { derecho. } \\
\text { Tienen, a mi juicio, la capacidad legal necesaria } \\
\text { para otorgar esta escritura de capitulaciones } \\
\text { matrimoniales. }\end{array}$ & $\begin{array}{l}\text { 1. Frau Barbara XXX } \\
\text { geboren am 14.11.19XX } \\
\text { wohnhaft in Weimar, XX-Str. XX } \\
\text { 2. Herr Frank XX } \\
\text { geboren am 23.07.XX } \\
\text { wohnhaft in Weimar, XX-Str. XX } \\
\text { Beide mir, Notar, persönlich bekannt. }\end{array}$ \\
\hline
\end{tabular}




\begin{tabular}{|c|c|}
\hline \multicolumn{2}{|c|}{ Exposición de hechos } \\
\hline $\begin{array}{l}\text {-EXPONEN- } \\
\text { I. Que contrajeron matrimonio en San Antonio } \\
\text { de Estoril-Carcais [sic] (Portugal), el día } 14 \text { de } \\
\text { abril de 1984, que se inscribió en el Registro } \\
\text { Civil del consulado General de España en } \\
\text { Lisboa, al tomo 33, página 173. } \\
\text { II. Que su matrimonio se ha venido rigiendo, } \\
\text { desde esa fecha, por el sistema de gananciales, } \\
\text { de conformidad con lo previsto en el artículo } \\
\text { 1.316 del Código Civil, puesto que hasta el día } \\
\text { de hoy no se ha otorgado contrato alguno } \\
\text { regulador de dicha sociedad conyugal. } \\
\text { [sigue la exposición de los distintos hechos, } \\
\text { enumerados con números romanos: I., II., III., } \\
\text { etc.] }\end{array}$ & \begin{tabular}{l}
\multicolumn{1}{c}{ I. } \\
\multicolumn{1}{|c}{ Sachstand } \\
Wir haben am 22.06.2001 in Würzburg \\
geheiratet. Zu diesem Zeitpunkt hatten wir \\
beide unseren ständigen Aufenthalt in \\
Deutschland. \\
Aus unserer Ehe ist bislang ein Kind \\
hervorgegangen, das am Leben ist, nämlich \\
Philipp, geb. am 04.XX.XX. \\
Wir haben bisher keine ehevertraglichen \\
Vereinbarungen getroffen \\
Wir besitzen beide die deutsche \\
Staatsangehörigkeit und haben kein \\
Auslandsvermögen. \\
[sigue la exposición de los distintos hechos]
\end{tabular} \\
\hline \multicolumn{2}{|c|}{$\begin{array}{ll}\text { Estipulaciones } \\
\end{array}$} \\
\hline $\begin{array}{l}\text { OTORGAN: } \\
\text { Que establecen como régimen económico de su } \\
\text { futuro matrimonio el de SEPARACIÓN } \\
\text { ABSOLUTA DE BIENES, que se regirá por lo } \\
\text { dispuesto en los artículos } 1.435 \text { a } 1.444 \text { del } \\
\text { Código Civil Español [...] } \\
\text { PRIMERO.- Cada cónyuge hace suyos con } \\
\text { independencia del otro los frutos de sus bienes } \\
\text { propios, si bien con la obligación de contribuir } \\
\text { al sostenimiento de las cargas del matrimonio } \\
\text { proporcionalmente a sus respectivos recursos } \\
\text { económicos. } \\
\text { [siguen las distintas cláusulas precedidas de } \\
\text { PRIMERO, SEGUNDO, TERCERO...] }\end{array}$ & 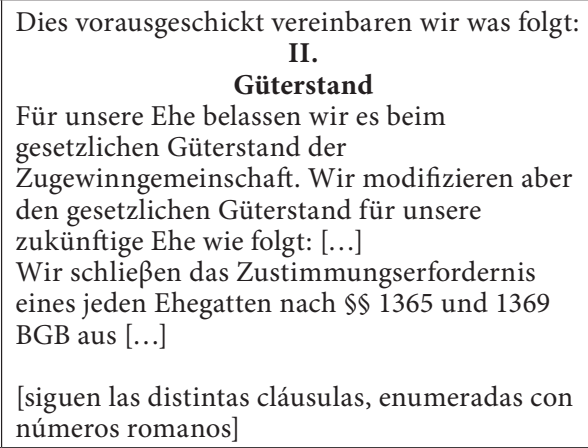 \\
\hline \multicolumn{2}{|c|}{ Otorgamiento y autorización } \\
\hline $\begin{array}{l}\text { OTORGAMIENTO Y AUTORIZACIÓN } \\
\text { Les permito la lectura de esta escritura por su } \\
\text { elección, después de advertidos de la opción del } \\
\text { Artículo } 193 \text { del Reglamento Notarial, previa } \\
\text { explicación por mí, el notario, a petición de los } \\
\text { interesados, de los extremos relevantes del } \\
\text { documento. Hacen constar su consentimiento y } \\
\text { la firman conmigo el Notario, que doy fe de } \\
\text { haberles identificado por sus documentos de } \\
\text { identidad que me han exhibido y antes } \\
\text { reseñados y, en lo pertinente, de cuanto se } \\
\text { expresa en este instrumento público que va } \\
\text { extendido sobre tres folios del Timbre del } \\
\text { Estado, de uso exclusivo para documentos } \\
\text { notariales, serie 7U, números 8210371, 8210372 } \\
\text { y 8210373. } \\
\text { Siguen las firmas de los comparecientes. } \\
\text { Signado: José Juan Pedreira Calleja. Rubricados. } \\
\text { Sellado. }\end{array}$ & $\begin{array}{l}\text { Vorgelesen vom Notar } \\
\text { von den Beteiligten genehmigt } \\
\text { und eigenhändig unterschrieben. }\end{array}$ \\
\hline
\end{tabular}

Aunque en este trabajo nos hayamos centrado en el análisis detallado de la macroestructura, como se puede apreciar en el cuadro 6, la comparación de los elementos microestructurales de las distintas secciones puede servir para identificar las características textuales tanto a nivel morfosintáctico (tiempos y formas verbales, dobletes léxicos, estilo nominal o verbal, conectores, etc.) como a nivel ortotipográfico (uso de mayúscula o negrita, ordenadores de párrafos, indicadores de capítulos 
o párrafos, etc.) y establecer las diferencias y similitudes que presenta esta clase textual en las dos culturas. Aquí nos limitamos a ofrecer algunos ejemplos:

- Vor dem unterzeichneten XXX Notar in XXX/ Ante mí, XXX, Notario del Ilustre Colegio Notarial de XXX

- erschienen heute/comparecen

- Sachstand/exponen

- dies vorausgeschickt vereinbaren wir was folgt/otorgan

- von den Beteiligten genehmigt und eigenhändig unterschrieben / hacen constar su consentimiento y la firman conmigo.

\section{Conclusiones}

Como ya se explicó en la Introducción de este trabajo, en el caso de la traducción del documento notarial capitulaciones matrimoniales al alemán o Ehevertrag al español, estamos ante un escenario de traducción jurídica interlingüística e intersistémica, que se caracteriza por la confrontación de dos culturas jurídicas y dos culturas textuales. El objetivo principal de este trabajo consistía en la adquisición de conocimientos comparados tanto jurídicos como textuales sobre estos documentos.

Del estudio jurídico hemos podido extraer las siguientes conclusiones:

La naturaleza y el contenido de estos documentos se presentan recogidos en el Código Civil y en el Bürgerliches Gesetzbuch, respectivamente, además de en las normas específicas que determinan las funciones notariales en cada país. En ambos textos, se regula principalmente el régimen económico del matrimonio, es decir, se establecen o se modifican las estipulaciones que han de regir la vida económica conyugal. No obstante, hemos podido comprobar que existen diferencias importantes entre ambos sistemas jurídicos, tanto en lo que se refiere al régimen económico legal (en la mayoría del territorio español: régimen de gananciales, en Alemania: Zugewinngemeinschaft o régimen de participación en las ganancias) como en lo que respecta a los regímenes económicos convencionales (en Alemania no existe en la actualidad el régimen de gananciales y en España la ley no conoce el de la Allgemeine Gütergemeinschaft o régimen de comunidad de bienes). Teniendo en cuenta estas diferencias, hemos propuesto posibles equivalencias entre los respectivos regímenes (ver cuadro 2).

En lo que se refiere al estudio textual, hemos constatado que no solo el contenido sino también la forma de los documentos se fija por ley. Hemos identificado las diferentes secciones de los documentos ateniéndonos tanto a las disposiciones reguladoras mencionadas como a los resultados del estudio del corpus textual analizado. El resultado obtenido muestra estructuras similares en los textos españoles y alemanes (ver cuadro 5).

Sin embargo, en el detalle de la microestructura es donde hemos podido apreciar notables diferencias en cuanto a las convenciones textuales, como se muestra en el contraste de los textos ofrecidos (ver cuadro 6). Sirva como ejemplo, en las secciones de encabezamiento y comparecencia, la presentación de los intervinientes en el acto notarial (notario y comparecientes), la identificación del documento, el tiempo verbal a través del que se presenta a los comparecientes, etc.

Una vez reunidos los datos, estimamos que ha quedado patente que ambos estudios comparados, el temático y el textual, posibilitan el establecimiento de las dife- 
rencias y las similitudes existentes entre los dos sistemas jurídicos y las dos culturas textuales, pertrechando, así, al traductor de los conocimientos temáticos y textuales necesarios para tomar, en función de otros parámetros como el encargo de traducción, decisiones de traducción razonadas. Ante este trasfondo, creemos poder confirmar la utilidad que tiene un enfoque jurídico y textual comparado en el ámbito de la traducción jurídica intersistémica e interlingüística.

\section{NOTAS}

1. Como apuntan Alcaraz Varó y Hughes (2002: 9), el tratamiento de las mayúsculas y minúsculas en la lengua española constituye un asunto en el que quedan todavía muchas preguntas abiertas. Sobre todo en lo que se refiere a la voz 'derecho' no existe unanimidad en cuanto a su correcta escritura. Para este trabajo hemos seguido las indicaciones de Martínez de Sousa (2007: 305) y escribimos derecho siempre con minúscula inicial, tanto cuando hace referencia al conjunto de principios y reglas que ordenan las relaciones humanas como cuando se refiere a la facultad de exigir algo que la ley establece en nuestro favor, como cuando se trata del nombre de la disciplina. No obstante, escribimos Derecho con mayúscula, para respetar las citas de los autores que así lo han preferido.

2. Son ejemplos la traducción de la legislación interna en países bilingües o plurilingües como Suiza o Finlandia, la traducción de una directiva europea a una de las lenguas oficiales de la Unión Europea o la traducción de una resolución del Consejo de Seguridad de la ONU de una lengua oficial a otra. En el primer caso, el sistema de referencia común es el derecho interno de un país, en el segundo caso, es el derecho comunitario y, en el tercer caso, el derecho internacional público.

3. Un ejemplo del ámbito del derecho de familia sería la figura de la separación judicial o legal, que existe en el derecho español, pero es desconocida en el derecho alemán (para más información, remitimos a Holl 2011a).

4. Las distintas técnicas de traducción para solventar dichas incongruencias conceptuales no forman parte del presente estudio. Para ellas remitimos a Mayoral Asensio (2003) y Martín Ruano (2005).

5. Con ello no queremos decir que el traductor deba respetar las convenciones textuales de la cultura de origen o de la cultura de llegada, ya que se trata de una cuestión muy compleja que depende de diferentes parámetros y que no pretendemos abarcar en el presente estudio (Borja Albi 1999).

6. Real Decreto de 24 de julio de 1889, texto de la edición del Código Civil mandada publicar en cumplimento de la Ley de 26 de mayo último. Consultado el 20 de septiembre de 2013, <http:// noticias.juridicas.com/base_datos/Privado/cc.html>.

7. Para más información sobre este concepto remitimos a Holl (2011a: 134 y ss).

8. En el ordenamiento jurídico español coexisten dos fuentes de derecho civil, a saber, el derecho civil común y el derecho civil foral. Aquí nos centraremos únicamente en la regulación prevista en el derecho civil común (artículos 1315 a 1444 CC). Para más información sobre los regímenes económicos de derecho foral se remite a Simó Santonja (2005: 219-243).

9. Aparte del divorcio, existen también otras causas que pueden llevar a la disolución del régimen de participación, como la muerte de uno de los cónyuges, las cuales no se tratarán aquí.

10. Finanztip. Consultado el 20 de septiembre de 2013, <http://www.finanztip.de/d/familienrecht/ Guetergemeinschaft.htm>.

11. Con Hurtado (2007: 211), entendemos la equivalencia traductora como un concepto relativo y dinámico que depende de condicionamientos textuales y de la finalidad de la traducción. Por tanto, no descartamos que en supuestos de traducción diferentes al escenario aquí planteado, como, por ejemplo, la traducción de un manual de derecho sobre los regímenes jurídicos matrimoniales existentes en España y/o Alemania, en vez de buscar equivalencias funcionales entre las figuras jurídicas de los dos regímenes legales implicados como hemos hecho en el caso de Gütertrennung y separación de bienes y Zugewinngemeinschaft y participación en las ganancias, puede ser necesario una técnica de traducción (Hurtado 2007: 256) distinta que permita que trasluzcan las diferencias, por muy pequeñas que estas sean (para más información sobre el concepto de equivalencia funcional en la traducción jurídica, véase también Holl 2012).

12. Para el análisis textual seguimos un modelo centrado en la comparación de la estructura externa organizada en secciones (Elena: 2004). Este modelo ha sido probado con anterioridad en trabajos relacionados con otras clases de textos del ámbito jurídico, como las sentencias de divorcio (véase Elena 2010 y Holl 2011a). 
13. Como, por ejemplo, también en el caso de las sentencias (véase Holl 2011a: 246 y ss.).

14. Escrituras, actas, pólizas y testimonios, en el derecho español; Niederschriften über Willenserklärungen y sonstige Niederschriften (Tatsachenbescheinigungen y Vermerke), en el derecho alemán (véase Holl 2011b).

15. La parte encabezamiento como tal no es denominada así en el RN. No obstante, autores como Jiménez Clar y Leyda Ern (2008: 117 y s.) la tratan como una sección propia, lo cual, desde nuestro punto de vista, facilita la comprensión de la organización externa del documento.

16. Para dejar constancia de las características ortotipográficas de los documentos, en la reproducción de los extractos de los documentos originales que componen el corpus, se respetan las particularidades ortotipográficas de estos (negrita, mayúscula, etc.).

17. Los datos personales de los otorgantes que puedan posibilitar su identificación se han tachado con «XX».

18. Oficina Notarial. Autorización de un instrumento público. Consultado el 20 de septiembre de 2013, $<$ http://www.oficinanotarial.com/2010/08/autorizacion-de-un-instrumento-publico.html $>$.

19. Para favorecer la legibilidad del presente estudio, ofrecemos la traducción al español de las secciones identificadas. La denominación en alemán se indica entre paréntesis.

\section{REFERENCIAS BIBLIOGRÁFICAS}

Alcaráz Varó, Enrique y Hughes, Brian (2002): El español jurídico. Barcelona: Ariel.

Borja Albi, Anabel (1999): La traducción jurídica. Didáctica y aspectos textuales. In: Antonio

Gil y Leo Hickey eds. Aproximaciones a la traducción. Madrid: Instituto Cervantes.

Consultado el 20 de septiembre de 2013, <http://cvc.cervantes.es/obref/aproximaciones/ borja.htm>.

Borja Albi, Anabel (2000): El texto jurídico inglés y su traducción al español. Barcelona: Ariel. Borja AlBi, Anabel (2005): Organización del conocimiento para la traducción jurídica a través de sistemas expertos basados en el concepto de género textual. In: Isabel GARCÍA IZQUIERDO, ed. El género textual y la traducción. Berna: Peter Lang, 37-76.

Bustos Moreno, Yolanda (2001): Las deudas gananciales y sus reintegros. Madrid: Dykinson.

CÁrCAba Fernández, María (1992): Las capitulaciones matrimoniales. Oviedo: Universidad de Oviedo.

Dannenberg-Mletzko, Lena y Baumgärtner-Wrede, Gerhard (2005): Notariatskunde. Wiesbaden: Gabler.

De Groot, Gérard-René (1991): Recht, Rechtssprache und Rechtssystem. Betrachtungen über die Problematik der Übersetzung juristischer Texte. Terminologie et Traduction. 3:279-316.

De La Rocha García, Ernesto (1999): Manual práctico de regímenes económicos matrimoniales. Granada: Comares.

Díez-Picazo, Luis y Gullón, Antonio (1998): Sistema de Derecho Civil. Vol. IV: Derecho de Familia. Derecho de Sucesiones. $7^{\text {a }}$ ed. Madrid: Tecnos.

Elena, Pilar (2004): La competencia textual en la traducción del documento público. In: Francisco J. García Marcos, et al. eds. Traducción, cultura e inmigración: reflexiones interdisciplinares. Granada: Atrio.

Elena, Pilar (2010): La lectura del texto jurídico basada en modelos textuales organizados. In: Icíar Alonso Araguás, et al. eds. Translating Justice. Traducir la Justicia. Granada: Comares, 73-83.

Fassbender, Hermann, Grauel, Walter, Ohmen, Werner et al. (2010): Notariatskunde. Rinteln: Merkur Verlag.

Femenía López, Pedro J. (2011): Capítulo II. De las capitulaciones matrimoniales. In: Joaquín Rams Albesa y Juan Antonio Moreno Martínez, eds. El régimen económico del matrimonio. Madrid: Dyckinson, 107-182.

Harvey, Malcolm (2000): A Beginner's Course in Legal Translation: the Case of Culture-bound Terms. In: ASTTI/ETI, ed. La Traduction Juridique: Histoire, theorie(s) et pratique. Berna, Ginebra: ASTTI/ETI, 357-369. Consultado el 20 de septiembre de 2013, <http://www. tradulex.com/Actes2000/harvey.pdf>. 
Heintschel-Heinegg von, Bernd y Gerhardt, Peter (2006): Materielles Scheidungsrecht. $8^{\mathrm{a}}$ ed. Múnich: Luchterhand.

Holl, Iris (2011a): Textología contrastiva, derecho comparado y traducción jurídica. Berlín: Frank \& Timme.

Holl, Iris (2011b): El documento notarial en España y en Alemania - un estudio contrastivo como ejercicio previo a la traducción. In: Silvia Roiss y Carlos Fortea et al. eds. En las vertientes de la traducción/interpretación del/al alemán. Berlín: Frank \& Timme, 407-430. Consultado el 20 de septiembre de 2013, <http://gredos.usal.es/jspui/bitstream/10366/ 112918/1/IRIS\%20-\%20El\%20documento\%20notarial\%20en.pdf>.

Holl, Iris (2012): Técnicas para la traducción jurídica: revisión de diferentes propuestas, últimas tendencias. Hermeneus. 14:191-216.

Hunn, Diether y SchucкмanN, Hans-Joachim (2003): Beurkundungsgesetz und Dienstordnung für Notare. Berlín: De Gruyter.

Hurtado Albir, Amparo (2007): Traducción y Traductología. Madrid: Cátedra.

Jiménez Clar, Antonio y Leyda Ern, Catalina (2008): Temas de Derecho Notarial. Valencia: Tirant lo blanch.

Lasarte, Carlos (2007): Derecho de Familia. Madrid/Barcelona/Buenos Aires: Marcial Pons.

Martín Ruano, M. Rosario (2005): La transmisión de la cultura en traducción jurídica: nuevas estrategias, éticas alternativas. In: María Torres Gracia y Marie-Ange Bugnot, eds. Traducción y cultura. El referente cultural en la comunicación especializada. Málaga: Encasa, 165-204.

Martínez De Sousa, José (2007): Manual de estilo de la lengua española. $3^{a}$ edición. Gijón: Trea.

Mayoral Asensio, Roberto (2003): Translating Official Documents. Manchester: St. Jerome.

Ribó Durán, Luis (2005): Diccionario de Derecho. $3^{\mathrm{a}}$ ed. Barcelona: Bosch.

Rohs, Günther y Heinemann, Diethard (2002): Die Geschäftsführung der Notare. Heidelberg: Decker.

ŠArČEviĆ, Susan. (1997): New Approach to Legal Translation. La Haya, Londres, Boston: Kluwer Law International.

Simó Santonja, Vicente L. (2005): Compendio de regímenes matrimoniales. Valencia: Tirant lo Blanch.

WEISFLOG, Walter (1996): Rechtsvergleichung und juristische Übersetzung: eine interdisziplinäre Studie. Zúrich: Schulthess.

Weston, Martin. (1991): An English Reader's Guide to the French Legal System. Nueva York/ Oxford: Berg.

\section{ANEXO: FUENTES DE LOS EJEMPLOS}

Beurkundungsgesetz. Consultado el 20 de septiembre de 2013, <http://www.bnotk.de/Notar/ Berufsrecht/BeurkG/index.php $>$.

Bürgerliches Gesetzbuch. Consultado el 20 de septiembre de 2013, http://dejure.org/gesetze/ $\mathrm{BGB} / 1410 . \mathrm{html}$.

Bundesnotarordnung. Consultado el 20 de septiembre de 2013, <http://www.bnotk.de/Notar/ Berufsrecht/BNotO/index.php>.

Dienstordnung für Notarinnen und Notare. Consultado el 20 de septiembre de 2013, <http:// www.bnotk.de/Notar/Berufsrecht/BNotO/BNotO_Teil_I.php\#Abschnitt_4>.

Ley del Notariado. Consultado el 20 de septiembre de 2013, <http://noticias.juridicas.com/ base_datos/Privado/ln.html>.

Reglamento Notarial. Consultado el 20 de septiembre de 2013, <http://noticias.juridicas.com/ base_datos/Privado/rn.t4.html\#cl>. 